analysis and the development of the soil profile; some of the results appeared in the Journal of Agricultural Science of 1930.

Meanwhile, other county soil surveys were being made in Britain by local officials working independently of each other without central co-ordination. The surveyors recognized the disadvantages, and established a Soils Correlation Committee, appointing Robinson as chairman. His wide reading and travel had familiarized him with the new ideas and methods developing in the United States, Europe, Russia and elsewhere, and his attractive persuasiveness enabled him to secure a uniform technique of mapping and nomenclature based on the soil profile; he introduced the 'suite' concept in soil classification and used it in Wales for designating his related soils as geologically genetic groups: these ideas and methods are now permanently embodied in soil-survey practice. Various papers on these subjects were elaborated and grew into his most important publication, "Soils, their Origin, Constitution and Classification" (Murby, 1938), now in its third edition (see Nature, June 3 , p. 866); the University of Cambridge had already in 1936 awarded him the Sc.D. degree for the work.

In 1939 the war conditions necessitated much government action in stimulating food production, and the disadvantages of independent surveys became manifest : it was, for example, impossible to construct a soil acidity map for Great Britain, although thousands of determinations had been made, but the various methods had not been comparable. The whole of the soil survey work was therefore brought under one control, and Robinson was the obvious choice for the directorship, holding this post, along with his professorship, until 1946, when the survey was transferred to Rothamsted Experimental Station. During this war period he was also adviser in agricultural chemistry to the North Wales province.

Robinson's work on soils, however, by no means claimed his whole attention. His breadth of culture was remarkable. In his early Bangor days he became friendly with one of the lecturers on the Classics, and proceeded to study them with such good effect that in 1928 he was elected president of the North Wales branch of the Classical Association, the only agricultural expert for generations who could have achieved such distinction. He had a great flair for modern languages, and could talk Welsh on the Welsh hills and some five or six other languages at international conferences, where his attractive personality made him always a most welcome visitor. In addition, he was a justice of the peace for Caernarvonshire, a member of the Central Advisory Council for Education in Wales (having already served on the Departmental Commission on Rural Education in Wales during 1928-30) and chairman of the Bangor Diocesan Religious Education Committee.

Robinson was twice married : first in 1913 to Winifred, daughter of Mr. J. Rushforth, who died in 1945 ; and secondly, in 1949 , to Mary Isabel, eldest daughter of the late Dr. H. L. James, Dean of Bangor. By the first marriage there was one son, now in Johannesburg, and three daughters.

He led an extraordinarily full and varied life, yet never seemed hurried or tired; he was a very acceptable member of any circle, whether a university senate, a social gathering or a golf club. Few men in the profession of agricultural science have been more trusted by their colleagues or held in more affectionate esteem than he was.
E. JohN RusSELL

\section{Dr. Herman Shaw}

Dr. Herman Shaw, director of the Science Museum, London, died suddenly at his home in Barnes on May 4. Born on October 14, 1891, he was educated at Bradford Grammar School, where he was a Governors' Scholar, and the Imperial College of Science and Technology, London, where he held a Royal Scholarship and, later, an Aeronautics Research Scholarship. During the First World War he served as a lieutenant in the R.N.V.R., a flight lieutenant in the R.N.A.S. and a captain in the R.A.F.

Shaw entered the Science Museum in 1920, and at once began to display evidence of his characteristic ability and energy. The Museum had acquired from Budapest in 1920 an example of an Eötvös torsion balance, and in 1921 Shaw received permission to make extensive tests on this; the work was carried out, in collaboration with E. Lancaster-Jones, in the basement of the Science Museum. In 1924-25 they carried out field tests with the torsion balance in Shropshire and at Hodbarrow, Cumberland, and were able to show its efficacy in the location and delineation of underground rock-structures. These experiments were the first of their kind to be carried out in Great Britain.

In 1928 Shaw and Lancaster-Jones designed their 'gravity gradiometer', a modified form of torsion balance designed specially for field-work and much smaller, lighter and quicker in operation than the conventional type of balance.

Shaw's interest in applied geophysics was a wide one, and by 1930 he was recognized as one of the leading authorities on the subject, with a world-wide reputation. Most of this geophysical work was carried out in his spare time, for he played his full part in the rapid development and extension of the Science Museum collections which took place during and after the occupation of the new building opened by H.M. King George V in 1928.

In 1931 Shaw was made a deputy keeper, and in 1935 he was promoted keeper of the Department of Physics and Geophysics. In 1940, in the absence on war service of the director, Colonel E. E. B. Mackintosh, he became acting director. In 1939 he had been put in charge of the A.R.P. arrangements in the Museum, and he also organised the evacuation to the country of the greater portion of the collections -a task of considerable magnitude and difficulty which he executed with great success. During the war period he also undertook several important geophysical surveys.

On Colonel Mackintosh's retirement in November 1945, Shaw succeeded him as director, and immediately threw himself with great energy into the task of rehabilitating the Museum collections. The Museum was partially re-opened in February 1946, and by the end of that year its post-war visitors had already totalled more than $1 \frac{1}{4}$ millions. The task of full restoration of the Museum and its services to the pre-war standard was a heavy one, but it is satisfying to know that, within the limits imposed by the rebuilding programme, Shaw was able to lead and guide it practically to completion before his untimely death. Shaw expected good work from his subordinates, but never attempted to drive them at the pressure at which he drove himself. As director he was kindly and accessible, and concerned for the welfare of his staff of all grades.

Shaw's publications included a text-book of aeronautics (1918); various official handbooks of the 
Science Museum; and about twenty papers in scientific journals, mainly on applied geophysics.

$\mathrm{He}$ was president of the Museums Association, honorary treasurer of the Physical Society, a trustee of the Imperial War Museum, a governor of the Imperial College and a manager of the Royal Institution.

He is survived by his widow; their only son died as a young man in 1946 .
F. A. B. WARD
WE regret to announce the following deaths :

Dr. P. N. Annand, chief of the Bureau of Entomology and Plant Quarantine, U.S. Department of Agriculture, on March 29, aged fifty-one.

Dr. Oskar Baudisch, director of research in the New York State Research Institute of Balneology and Hydrotherapy since 1934, known for work on cupferron and neo-cupferron as analytical reagents, on March 28, aged sixty-eight.

\section{NEWS and VIEWS}

University College of North Staffordshire :

Prof. A. R. Gemmell

DR. A. R. GEMmeLL, who was recently elected to the chair of biology in the University College of North Staffordshire, is thirty-seven years of age. He received his training in the University of Glasgow and later, as a Commonwealth Fund Fellow, in the University of Minnesota. Dr. Gemmell has a wide experience in biology, for he has held a post in the Forensic Science Department of the Home Office, a lectureship in plant pathology and physiology in the University of Glasgow, and he is at present lecturer in botany in the University of Manchester. His early research was in the field of plant pathology ; recently he has turned his attention to bryophytes, and he has made original and interesting observations both on their physiology and on their geographical distribution. In Manchester, Dr. Gemmell has played an important part in broadening the scope of teaching in the faculty of science and in dealing with student affairs. Both in experience and temperament he is well equipped to take part in the ambitious experiment of founding a university with unusual aims and exceptional opportunities.

\section{Dr. A. Mittasch's Eightieth Birthday}

Dr. Alwin Mrtiasch, whose eightieth birthday was celebrated recently in Heidelberg, is well known in the world of chemistry for his pioneering work on catalysis and his connexion with the Haber nitrogenfixation process. Having studied catalysis under Ostwald, he became a collaborator of Carl Bosch in the Badische Anilinfabrik, Ludwigshafen, and after innumerable experiments he succeeded in discovering the suitable catalysing agents which made it possible to apply the Haber process commercially. Dr. Mittasch enjoyed for a long time the exceptional distinction of being a member of the Heidelberg Academy of Sciences without ever having taught at a university, and it was only on the occasion of his eightieth anniversary that he was awarded the title of professor. His far-reaching researches on catalysis have led him beyond the boundaries of chemistry; for example, he has made a deep study of the distinction between release causality, which is that observed in catalysis, and the ordinary mechanical causality-a distinction which was particularly emphasized by Robert Mayer. Altogether, he has written a number of books on chemistry and related subjects. One of his most recent works, "From Chemistry to Philosophy", which was published in 1948, is a collection of easays, the first part of which deals with catalysis in its widest aspect, the second with causality in Nature, and the third with Schopenhauer, Robert Mayer and Nietzsche. Probably Dr. Mittasch's most recent publication is an article on "The Other Nietzsche", which contrins the following Nietzsche quotation: "The continuance of Christian ideals is one of the most desirable things. (Only the tyranny should stop.)"

\section{Honours to Swedish Oceanographers}

Prof. Hans Petrersson, director of the Oceanographical Institute, Gothenburg, has recently been awarded the Vega Medal of the Royal Geographical Society of Sweden and also the Galather Medal of the Royal Danish Geographical Society. The former honour is named after the Swedish expedition in the Vega, which, with the explorer Adolf Erik Nordenskjöld as leader, was the first to sail through the North-East Passage in 1878-80, and the Medal is awarded annuslly in recognition of prominent achievements in the field of exploration. The latter, named after a Danish corvette which in 1845-47 circumnavigated the globe carrying a party of scientific workers engaged in geographical and oceanographical investigations, is awarded for services to these sciences. Prof. Pettersson is an internationally known authority on oceanography and was the leader of the Swedish Deep-Sea Expedition in the round-the-world voyage of the Albatross during 1947-48 (see Nature, 160, 559; 1947, and 162,$324 ; 1948$ ); for this work he was awarded the Patron's Medal for 1949 of the Royal Geographical Society (of Great Britain) (seo Nature, 163,$595 ; 1949$ ). His close associate and compatriot, Dr. B. Kullenberg, to whom is due the piston coresampler which was the main tool on the Albatross expedition in the investigation of the deep-ocean floor, has been awarded the Wahlberg Gold Medal for his services to the cause of marine research. Previous recipients of this honour, which is given by the Swedish Society for Anthropology and Geography, include Sven Hedin and Erik Nordenskjöld.

\section{Western Union Cultural Identity Cards}

A CULTURal identity card has been instituted by the Brussels Treaty Organisation, which will give certain facilities and privileges to nationals of each of the five Treaty countries when travelling in the other four for cultural purposes. In Article III of the Brussels Treaty, Belgium, France, Luxembourg, the Netherlands and the United Kingdom undertook to strengthen their cultural relations with each other. They have therefore made it one of their first tasks. to encourage travelling and residence abroad by teachers, research workers, artists and men of science, for visits associated with the improvement of their professional knowledge or with research work. The 